\title{
ENRIQUECIMENTO AMBIENTAL X COMPORTAMENTO EM CATIVEIRO DE CALLITHRIX AURITA (É. Geoffroy, 1812)
}

\author{
Marcellus Pereira Souza ${ }^{1}$ \\ Karla Andressa Ruiz Lopes ${ }^{2}$ \\ Nádia Maria Rodrigues de Campos Velho ${ }^{3}$
}

\begin{abstract}
Resumo: Técnicas de enriquecimento ambiental foram utilizadas para avaliação dos comportamentos em cativeiro de um grupo de três indivíduos, duas fêmeas e um macho de Callithrix aurita (sagui-da-serraescuro), cativos do Mantenedor de Fauna Silvestre da UNIVAP, São José dos Campos, SP. Foram implantados seis diferentes enriquecimentos alimentares e observações com duração de uma hora pelo método "focal sampling grupal" no período de agosto a novembro de 2015. Os comportamentos categorizados, inicialmente, eram Alimentação, Alerta, Comunicação, Social, Manutenção e Território. A categoria Cuidado Parental foi adicionada após o nascimento de dois filhotes. Percebeu-se que Alimentação e Alerta foram as categorias mais evidentes, que Cuidado Parental apareceu equilibrada entre os membros e as expressões de comportamentos típicos foram significantes para concluir que enriquecimentos ambientais melhoram o bem-estar animal de animal em cativeiro.
\end{abstract}

Palavras-chave: Sagui-da-Serra-Escuro; Bem-estar; Etologia; ex-situ.

\footnotetext{
${ }^{1}$ Ciências Biológicas/Universidade do Vale do Paraíba, Brasil. E-mail: marcelluspsouza@gmail.com.

2 Ciências Biológicas/Universidade do Vale do Paraíba, Brasil. E-mail: karla@univap.br.

${ }^{3}$ Ciências Biológicas/Universidade do Vale do Paraíba, Brasil. E-mail: nvelho@univap.br.
} 